\title{
Housing characteristics and indoor environment in relation to children's asthma, allergic diseases and pneumonia in Urumqi, China
}

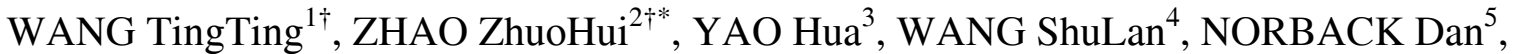 \\ CHEN Jie ${ }^{6}$, MA JinFeng ${ }^{1}, \mathrm{JI}_{\mathrm{XiaoLi}}{ }^{1}, \mathrm{WANG} \mathrm{Li}^{1}$ \& SUNDELL Jan ${ }^{7}$ \\ ${ }^{1}$ Department of Maternal, Child and Adolescent Health, School of Public Health, Xinjiang Medical University, Urumqi 830011, China; \\ ${ }^{2}$ Department of Environmental Health, Key Laboratory of Public Health Safety, Ministry of Education, School of Public Health, Fudan \\ University, Shanghai 200032, China; \\ ${ }^{3}$ The First Hospital Affiliated to Xinjiang Medical University, Urumqi 830011, China; \\ ${ }^{4}$ Center for Education Research, Urumqi 830011, China; \\ ${ }^{5}$ Department of Medical Sciences, Occupational and Environmental Medicine, Uppsala University, Uppsala SE-751, Sweden; \\ ${ }^{6}$ School of Management, Fudan University, Shanghai 200433, China; \\ ${ }^{7}$ Department of Building Science and Technology, Tsinghua University, Beijing 100084, China
}

Received October 17, 2012; accepted December 14, 2012; published online May 28, 2013

\begin{abstract}
In order to evaluate the prevalence of childhood asthma, allergic diseases and pneumonia in Urumqi City, China, as well as its associations with housing and home characteristics, a cross-sectional study was performed in 4618 children $(81.7 \%$ response rate, average age $4.7 \pm 0.9$ year, boys accounting for $53.7 \%$ ). Questions on children's asthma and allergic diseases were from the International Study on Asthma and Allergies in Childhood (ISAAC) and were integrated with questions on the home environment from the Dampness in Buildings and Health (DBH) study, slightly modified to account for Chinese building characteristics and life habits. The prevalences of physician diagnosed asthma, allergic rhinitis (AR) and pneumonia were 3.6\%, 8.7\% and 40.9\%, respectively. One fourth of children reported wheezing and more than $40 \%$ AR symptoms in the last 12 months. Controlling for confounding factors, positive associations were found for home mold/dampness and wheezing (adjusted odds ratio, aOR 1.33, 95\% CI 1.07-1.66), AR symptoms (1.34, 1.09-1.64) last 12 months and physician diagnosed pneumonia $(1.33,1.09-1.62)$. Floor material by wood, PVC or carpeting; and walls by wallpaper, painting or wood material, were positively associated with AR symptoms. Home environmental tobacco smoke (ETS) was positively associated with wheezing $(1.23,1.04-1.46)$ and pneumonia $(1.25,1.07-1.45)$. In conclusion, there was a relatively high prevalence of asthmatic and AR symptoms and diagnosed pneumonia in preschool children in Urumqi. Home signs of mold growth or dampness, windowpane condensation, as well as ETS and interior surface materials emitting chemicals were risk factors for allergic symptoms and pneumonia.
\end{abstract}

childhood, dampness, indoor air quality, prevalence, environmental tobacco smoking

Citation: Wang T T, Zhao Z H, Yao H, et al. Housing characteristics and indoor environment in relation to children's asthma, allergic diseases and pneumonia in Urumqi, China. Chin Sci Bull, 2013, 58: 4237-4244, doi: 10.1007/s11434-013-5727-0

With the prevalence of childhood asthma and allergic diseases increasing worldwide over the past decades, it is widely accepted that environmental factors, in addition to genetics, are closely related with allergic diseases. Concurrent with China's rapid economic growth and social development, there has been a great increase of childhood asthma

\footnotetext{
$\uparrow$ These authors contributed equally to this work.

*Corresponding author (email: zhzhao@fudan.edu.cn)
}

and allergic diseases [1,2]. Most studies of asthma and allergy in China have been performed in the east or middle part, with few studies from the northwest, an area relatively less economically developed and with more severe geographical and climate conditions.

The Urumqi city $\left(86^{\circ} 37^{\prime} 33^{\prime \prime}-88^{\circ} 58^{\prime} 24^{\prime \prime} \mathrm{E}, 42^{\circ} 45^{\prime} 32^{\prime \prime}-\right.$ $\left.44^{\circ} 08^{\prime} 00^{\prime \prime} \mathrm{N}\right)$, capital of Xinjiang Uygur Autonomous Region of China, is located in northwest China. Situated on the 
northern piedmont plains of the Tianshan Mountains at about $800 \mathrm{~m}$ above sea level, Urumqi has a permanent residential population of over 2.5 million which is steadily increasing. In the past decade, Urumqi has undergone rapid economic development with an average $10.3 \%$ increase of Gross Domestic Product (GDP) per year in 2001-2010. Fossil fuel is the major energy source supporting the economic development with coal energy accounting for $65.9 \%$ in 2009 , followed by crude oil at $16.9 \%$ in 2009 [3]. In 1998, the city was evaluated as one of the 10 heaviest air-polluted cities over the world [4]. It has been reported that the mean annual (2001-2006) concentrations for $\mathrm{PM}_{10}$ was ranging from 150 to $240 \mu \mathrm{g} / \mathrm{m}^{3}, \mathrm{NO}_{2}$ from 31 to $50 \mu \mathrm{g} / \mathrm{m}^{3}$, and $\mathrm{SO}_{2}$ from 49 to $160 \mu \mathrm{g} / \mathrm{m}^{3}$ [5].

National surveys in 1990 and 2000 on the prevalence of diagnosed asthma in Chinese children aged 0-14 years old found the prevalence of asthma in Urumqi was $0.4 \%$ and $0.61 \%$, respectively [2]. A survey using the International Study on Asthma and Allergies in Childhood (ISAAC) questionnaire, found that the prevalence of Allergic Rhinitis (AR) increased from $14.5 \%$ in 1992 to $18.9 \%$ in 2002 in 13-14 years children [6]. However, little has been reported on the prevalence of asthma or allergic diseases in younger children. Given the high rate of economic development, people's lives, including housing characteristics and aspects of indoor environment are expected to change from a traditional style towards a more modern and westernized style.

The aims of this study are firstly, to quantify the prevalence of asthma, AR and eczema in preschool children in Urumqi City and secondly, to evaluate associations between children's asthma, allergic diseases and symptoms and housing characteristics and the indoor environment.

\section{Methods and materials}

\subsection{Subjects}

Using a cross-sectional study design, children were selected by a stratified random cluster sampling method in day care centers in Urumqi. Stratified by 7 administrative areas in Urumqi (including Xinshi, Tianshan, Toutunhe, Sayibak, Midong, Shuimogou and Urumqi county), 2 to 4 day care centers in each administrative area were randomly selected. All children in each day care center were invited to participate the questionnaire survey. A total of 5650 children in 18 day care centers received the questionnaire. The ethnic distribution of responders was primarily Han, with less Minority people, mainly composed of the Uygurs ethnic people, Kazaks people and other unnamed minorities people, accounting for around $17.4 \%$. The survey was performed in the winter season in 2011.

\subsection{Questionnaire}

The questionnaire survey was performed in day care centers.
All directors of day care centers who were asked agreed to participate. The questionnaires were distributed by teachers in each class to all students. Parents or legal guardian responded to the questionnaires, and the teachers collected completed questionnaires from the children.

The questionnaire, used in this study-China, Children, Homes, Health $(\mathrm{CCHH})$, are basically the same used in studies previously in Sweden [7], Bulgaria [8], Singapore [9], USA [10], and in ongoing studies in Taiwan, China, [11], South Korea, and Denmark. It includes several sets of questions. The first set of questions was about children's demographics, family and personal life factors, including children's date of birth, gender, nationality, breastfeeding, mother's of father's allergic diseases (genetics). The second set of questions was about the housing characteristics and the home environment. Part of the questionnaire was modified to reflect what differs in China from previously studied in western countries. The third set of questions was on children's asthma and allergic diseases including AR and eczema, as well as pneumonia.

Questions on genetic factors addressed parental allergic disease history, namely father's or mother's reported asthma, AR and eczema. Questions on housing characteristics (Table 1) included the home's location in urban or suburban/rural areas; dwelling type; surrounding area; proximity to traffic, industry or commercial area; dwelling size; construction year and ownership. Questions on home interior characteristics included nature of floor and wall materials, heating system and cooking fuel. The final set of questions was about mold growth or signs of dampness in children's sleeping room; windowpane condensation in winter season and home environmental tobacco smoke (home ETS) and pet-keeping at home. ETS refers to smoking by any person who lives with the child. Questions on children's asthma or related allergic diseases were from the ISAAC core questionnaire. The health problems of interest in this study were physician diagnosed asthma, AR and eczema and their related symptoms in the last 12 months, and diagnosed pneumonia. The ISAAC questionnaire has been previously used for Chinese children [12-14] and validated by clinical investigation [15].

\subsection{Data analysis}

The data were input with Epidate 3.1 software. A Chisquare test examined differences in the prevalence stratified by gender, nationality, age and environmental factors. Multivariate logistic regression analyzed associations between housing characteristics and children's asthma, AR, eczema, symptoms of these diseases, and pneumonia, controlling for age, gender, nationality, parental allergic diseases, put bedding to sunshine and cleaning frequently. In all statistical analyses, two-tailed tests and a 5\% significance level was applied. The analyses were performed by SPSS 11.5 
Table 1 Definition of housing characteristics and home environment in questionnaire survey in Urumqi

\begin{tabular}{|c|c|}
\hline Environmental factors & Definitions \\
\hline Dwelling location & The place where children's homes were located. Categorized as urban and suburban/rural areas \\
\hline Surrounding area within $200 \mathrm{~m}$ & $\begin{array}{l}\text { The main characteristics surrounding the children's home within } 200 \mathrm{~m} \text { including traffic, commercial/industrial } \\
\text { or other environment including river/lakes }\end{array}$ \\
\hline Dwelling type & $\begin{array}{l}\text { Single-family dwelling refers to a Pingfang (single house with a yard in Chinese style), villa or any other kind of } \\
\text { single family house; multi-family dwelling referred to high buildings with many storeys and } 2 \text { or more fami- } \\
\text { lies in each storey }\end{array}$ \\
\hline Dwelling owner & Whether the house was owned by the children's parents or by other people who the family rent from \\
\hline Floor material & $\begin{array}{l}\text { Floor made of wood or bamboo, PVC (polyvinyl chloride polymer), or carpeting (door-to-door carpet covering), } \\
\text { concrete/tiles or stones in children's sleeping room }\end{array}$ \\
\hline Wall materials & $\begin{array}{l}\text { The wall surface of wood, and/or covered by wallpaper, oil paint or water-based paint in children's sleeping } \\
\text { room }\end{array}$ \\
\hline Heating system & $\begin{array}{l}\text { Central heating refers to the heating system which transports warm water to homes by pipes from a supply cen- } \\
\text { ter; other heating systems include coal-burning stove, Kang (a heatable brick bed), fireplace, firebasin, floor } \\
\text { heating or air conditioning }\end{array}$ \\
\hline Mold/dampness & $\begin{array}{l}\text { Signs of mold growth, or signs of dampness, water condensation, and water cracks in the walls, floors or ceil- } \\
\text { ings in the children's sleeping room }\end{array}$ \\
\hline Water condensation & Water condensation on the window panes in the children's sleeping room in winter season. \\
\hline Home ETS & $\begin{array}{l}\text { Home environmental tobacco smoke, cigarette smoking by father, mother, grandparents or other people who live } \\
\text { with the children }\end{array}$ \\
\hline Current pet-keeping & Currently cat or dog in home \\
\hline
\end{tabular}

(Chicago, USA).

\section{Results}

Out of the 5650 invited children, 4618 children were recruited (response rate $81.7 \%$ ) (Table 2). The average age was $4.7 \pm 0.9$ years, with boys accounting for $53.7 \%$. The total prevalence of physician diagnosed asthma was $3.6 \%$, and $25 \%$ of children reported wheezing in the last 12 months. More than $40 \%$ of children reported AR symptoms in the last 12 months and $8.7 \%$ were diagnosed with AR. A lower proportion of $13.0 \%$, reported eczema symptoms in the last 12 months. Additionally, $41 \%$ of children had been diagnosed with pneumonia.

Boys generally had higher prevalences of symptoms and diseases than girls, including wheezing ever, AR ever and rhinitis symptoms as well as diagnosed asthma, AR and pneumonia (Table 2). Younger children had generally more symptoms than older ones. For example, $28.7 \%$ of the children in the youngest age group $(2 \leqslant$ age $<4$ years) had wheezing in the last 12 months, higher than $24.7 \%$ in the older group ( $4 \leqslant$ age $<5$ years) and $21.8 \%$ in the oldest group $(5 \leqslant$ age $<7$ years $)(P<0.001)$. On the other hand, physician diagnosed asthma, AR and pneumonia were highest in the oldest age group. Additionally, the prevalence differences between Han and Minority people were small on eczema symptoms and diagnosed pneumonia. The Han children had higher prevalence of eczema ever ( $15.0 \%$ vs. $10.3 \%, P=0.001)$ and eczema symptoms $(13.8 \%$ vs. $9.4 \%, P=0.001)$ in the last 12 months, as well as pneumonia ( $42.0 \%$ vs. $35.4 \%, P=0.001)$.

Most children (80.8\%) lived in the urban areas in Urumqi and half of those were close to traffic, commercial or industrial areas $(49.1 \%)$. More than half $(54.4 \%)$ of the houses were constructed later than the year of 2001. Almost half of the people used either wood/bamboo or concrete/tiles as floor material, and very few used PVC (1.9\%) or carpeting $(3.7 \%)$. More than $80 \%$ of homes used electricity or gas as

Table 2 Prevalence (\%) of asthma and allergic diseases stratified by nationality, age and gender in pre-school children in Urumqi, China

\begin{tabular}{|c|c|c|c|c|c|c|c|c|c|c|c|}
\hline & \multirow[b]{2}{*}{$\begin{array}{c}\text { Total } \\
(n=4618)\end{array}$} & \multicolumn{2}{|c|}{ Nationality $^{\text {a) }}$} & \multirow{2}{*}{$P$} & \multicolumn{2}{|c|}{ Gender } & \multirow{2}{*}{$P$} & \multicolumn{3}{|c|}{ Age } & \multirow{2}{*}{$P$} \\
\hline & & $\begin{array}{c}\text { Han } \\
(n=3756)\end{array}$ & $\begin{array}{l}\text { Minority } \\
(n=804)\end{array}$ & & $\begin{array}{c}\text { Boys } \\
(n=2477)\end{array}$ & $\begin{array}{c}\text { Girls } \\
(n=2134)\end{array}$ & & $\begin{array}{c}2 \leqslant \text { age }<4 \text { years } \\
\quad(n=1156)\end{array}$ & $\begin{array}{c}4 \leqslant \text { age }<5 \text { years } \\
\quad(n=1564)\end{array}$ & $\begin{array}{c}5 \leqslant \text { age }<7 \text { years } \\
\quad(n=1627)\end{array}$ & \\
\hline \multicolumn{12}{|c|}{ Asthma, allergic diseases and related symptoms } \\
\hline Wheezing ever & 34.9 & 35.0 & 34.8 & 0.933 & 37.2 & 32.3 & 0.001 & 38.0 & 34.1 & 33.8 & 0.053 \\
\hline Wheezing last 12 months & 24.7 & 24.6 & 25.1 & 0.753 & 25.5 & 23.8 & 0.199 & 28.7 & 24.7 & 21.8 & 0.000 \\
\hline Dry cough last 12 months & 11.5 & 11.5 & 11.8 & 0.790 & 11.8 & 11.4 & 0.762 & 12.1 & 11.5 & 11.1 & 0.740 \\
\hline Allergic rhinitis ever & 47.7 & 48.0 & 47.0 & 0.383 & 49.4 & 45.8 & 0.019 & 46.5 & 47.0 & 49.9 & 0.153 \\
\hline AR last 12 months & 42.8 & 43.3 & 40.5 & 0.160 & 44.3 & 41.0 & 0.030 & 43.9 & 42.1 & 43.1 & 0.669 \\
\hline Eczema ever & 15.0 & 15.7 & 11.3 & 0.003 & 16.0 & 13.8 & 0.059 & 15.4 & 15.0 & 14.8 & 0.932 \\
\hline Eczema last 12 months & 13.0 & 13.8 & 9.4 & 0.001 & 12.8 & 13.4 & 0.583 & 16.7 & 11.3 & 12.0 & 0.000 \\
\hline \multicolumn{12}{|c|}{ Physician diagnosed asthma, rhinitis and pneumonia } \\
\hline Physician diagnosed asthma & 3.6 & 3.5 & 4.1 & 0.387 & 4.7 & 2.4 & 0.000 & 2.8 & 3.0 & 4.7 & 0.009 \\
\hline Diagnosed Allergic rhinitis & 8.7 & 8.8 & 7.9 & 0.453 & 9.5 & 7.6 & 0.030 & 5.1 & 9.0 & 10.8 & 0.000 \\
\hline Pneumonia & 40.9 & 42.0 & 35.4 & 0.001 & 42.8 & 38.6 & 0.005 & 38.0 & 43.2 & 41.6 & 0.025 \\
\hline
\end{tabular}

a) Refers to Han and minority people. Minority people included mainly Uygur ethnic people, Kazak and other unknown minorities. 
cooking fuel and $70 \%$ had central heating system. ETS exposure was relatively common (55.0\%). Few homes have cats or dogs as pets $(2.1 \%)$. Compared to minority people (Table 3), Han children tended to live more in multi-unit buildings $(66.1 \%$ vs. $58.3 \%)$, with larger living area $(>75$ $\mathrm{m}^{2}$ by $58.8 \%$ vs. $54.9 \%$ ) but Han families less owned the house $(72.7 \%$ vs. $76.9 \%)$. With respect to home interior characteristics, minority people used more carpeting (16.2\% vs. $1.4 \%$ ), more coal/wood as cooking fuel (compared with electricity or gas) and kept more cats or dogs (3.4\% vs. $2.0 \%)$. Windowpane condensation in winter season was more often reported by the Han people (42.0\% vs. $37.2 \%)$.
Multivariate logistic regression analyses were performed for housing characteristics and the home environment in relation to children's asthma or allergic diseases (Table 4). Controlling for age, gender, nationality and parental asthma/AR/eczema, putting bedding to sunshine and home cleaning frequently (equal to or more than 1 time/week), consistent associations were found between home mold/ dampness (referred to without home mold/dampness) and wheezing (adjusted odds ratio, aOR 1.33, 95\% CI 1.07-1.66), AR symptoms in the last 12 months (aOR 1.34, 95\% CI 1.09-1.64) and physician diagnosed pneumonia (aOR 1.33, 1.09-1.62). Windowpane condensation in the

Table 3 Housing characteristics and home environment in pre-school children in the Han and minority people in Urumqi, China ${ }^{\text {a) }}$

\begin{tabular}{|c|c|c|c|c|c|}
\hline & Total $(n)$ & Proportion (\%) & $\operatorname{Han}(\%)$ & Minority $^{\mathrm{b})}(\%)$ & $P$ \\
\hline \multicolumn{6}{|l|}{ Dwelling location } \\
\hline Urban & 3730 & 80.8 & 85.3 & 84.4 & \\
\hline Suburban/rural & 649 & 14.1 & 14.7 & 15.6 & 0.529 \\
\hline Traffic & 1037 & 22.5 & 24.9 & 21.8 & \\
\hline Business/industrial & 1040 & 22.5 & 24.8 & 23.5 & \\
\hline Other environment & 2151 & 46.6 & 50.2 & 54.7 & 0.082 \\
\hline \multicolumn{6}{|l|}{ Dwelling type } \\
\hline Single-family dwelling & 1487 & 32.2 & 33.9 & 41.7 & \\
\hline Multi-unit building & 2739 & 59.3 & 66.1 & 58.3 & 0.000 \\
\hline \multicolumn{6}{|l|}{ Dwelling construction year } \\
\hline Earlier than 2000 & 1759 & 38.1 & 41.1 & 42.3 & \\
\hline 2001-now & 2514 & 54.4 & 58.9 & 57.7 & 0.547 \\
\hline \multicolumn{6}{|l|}{ Area of dwelling } \\
\hline$\leqslant 75 \mathrm{~m}^{2}$ & 1840 & 39.8 & 41.2 & 45.1 & \\
\hline$>75 \mathrm{~m}^{2}$ & 2557 & 55.4 & 58.8 & 54.9 & 0.048 \\
\hline Yes & 3198 & 69.3 & 72.7 & 76.9 & \\
\hline No & 1160 & 25.1 & 27.3 & 23.1 & 0.018 \\
\hline \multicolumn{6}{|c|}{ Floor material in children's sleeping room } \\
\hline Wood/bamboo & 1974 & 42.7 & 45.1 & 45.1 & \\
\hline Concrete/tiles & 2109 & 45.7 & 50.3 & 37.3 & \\
\hline PVC & 88 & 1.9 & 2.3 & 0.7 & \\
\hline Carpeting & 172 & 3.7 & 1.4 & 16.2 & \\
\hline Others & 38 & 0.8 & 0.9 & 0.7 & 0.000 \\
\hline \multicolumn{6}{|c|}{ Wall material in children's sleeping room } \\
\hline Wallpaper/painting/wood & 3729 & 80.7 & 87.9 & 88.1 & \\
\hline Concrete/stones & 513 & 11.1 & 12.1 & 11.9 & 0.857 \\
\hline \multicolumn{6}{|l|}{ Heating } \\
\hline Central heating & 3174 & 68.7 & 71.9 & 65.9 & \\
\hline Others & 1313 & 28.4 & 28.1 & 34.1 & 0.001 \\
\hline \multicolumn{6}{|l|}{ Cooking fuel } \\
\hline Electricity/gas & 3897 & 84.4 & 89.3 & 86.3 & \\
\hline Yes & 688 & 14.9 & 17.2 & 15.1 & \\
\hline No & 3418 & 74.0 & 82.8 & 84.9 & 0.178 \\
\hline \multicolumn{6}{|c|}{ Windowpane water condensation in children's sleeping room } \\
\hline Yes & 1628 & 35.3 & 42.0 & 37.2 & \\
\hline No & 2342 & 50.7 & 58.0 & 62.8 & 0.024 \\
\hline \multicolumn{6}{|l|}{ Home ETS ${ }^{c)}$} \\
\hline Yes & 2540 & 55.0 & 57.4 & 59.8 & \\
\hline No & 1867 & 40.4 & 42.6 & 40.2 & 0.227 \\
\hline \multicolumn{6}{|l|}{ Current pet-keeping } \\
\hline Cat or dog & 99 & 2.1 & 2.0 & 3.4 & \\
\hline Not keeping cat/dog & 4316 & 93.5 & 98.0 & 96.6 & 0.014 \\
\hline
\end{tabular}

a) The numerical data in sub-groups might not add to the total number of participating children due to missing data. Similarly, the proportional value (\%) may not add to $100 \%$ due to missing data; b) minority people mainly include the Uygur ethnic people, Kazak and other unknown minorities; c) ETS, environmental tobacco smoke, refers to the cigarette smoking by people who live with the children. 
Table 4 Associations between asthma or related symptoms and diseases and housing characteristics (aOR, 95\%CI) ${ }^{a}$

\begin{tabular}{|c|c|c|c|c|c|c|c|}
\hline & Wheezing 12 m & Dry cough $12 \mathrm{~m}$ & AR $12 \mathrm{~m}$ & Eczema $12 \mathrm{~m}$ & DA & DAR & DP \\
\hline Live in urban & $1.03(0.80-1.33)$ & $0.68(0.50-0.92)^{\mathbf{b})}$ & $0.95(0.76-1.18)$ & $1.38(0.97-1.97)$ & $1.19(0.63-2.25)$ & $1.49(0.94-2.36)$ & $0.81(0.65-1.01)$ \\
\hline $\begin{array}{l}\text { Close to traffic/ } \\
\text { industry/business }\end{array}$ & $10(0.93-1.31)$ & $20(0.96-151)$ & $07(0.93-1.24)$ & $0.94(0.76-1.17)$ & $1.04(0.70-1.54)$ & $1.03(0.79-1.34)$ & $1.13(0.98-1.31)$ \\
\hline Own house & $0.93(0.77-1.14)$ & $1.10(0.83-1.44)$ & $1.13(0.95-1.35)$ & $0.95(0.73-1.22)$ & $0.93(0.59-1.48)$ & $1.10(0.79-1.52)$ & $1.11(0.93-1.32)$ \\
\hline $\begin{array}{l}\text { Wood/PVC/carpeting } \\
\text { floor }\end{array}$ & $1.03(0.87-1.23)$ & $1.14(0.90-1.44)$ & $1.17(1.01-1.31)^{\mathrm{b})}$ & $1.05(0.84-1.31)$ & $0.67(0.44-1.01)$ & $1.46(1.11-1.92)^{\mathrm{c})}$ & $1.15(0.99-1.34)$ \\
\hline $\begin{array}{l}\text { Wallpaper/painting/ } \\
\text { wood wall }\end{array}$ & $1.04(0.80-1.36)$ & $1.01(0.70-1.47)$ & $1.35(1.07-1.72)^{\mathrm{b})}$ & $\left.0.72(0.53-0.99)^{b}\right)$ & $0.92(0.50-1.69)$ & $0.97(0.63-1.50)$ & $0.94(0.74-1.18)$ \\
\hline Central heating & $0.89(0.73-1.07)$ & $0.90(0.70-1.16)$ & $\left.0.84(0.71-0.99)^{b}\right)$ & $0.64(0.51-0.81)^{\mathrm{d})}$ & $1.04(0.66-1.63)$ & $0.72(0.54-0.95)^{\mathrm{b})}$ & $1.24(1.05-1.47)^{\mathrm{b})}$ \\
\hline $\begin{array}{l}\text { Gas/electricity for } \\
\text { cooking }\end{array}$ & $0.89(0.67-1.18)$ & $1.44(0.95-2.16)$ & $1.23(0.95-1.57)$ & $0.85(0.69-1.06)$ & $1.54(0.68-3.47)$ & $1.30(0.78-2.13)$ & $1.03(0.80-1.32)$ \\
\hline Home ETS & $1.23(1.04-1.46)^{\mathrm{b})}$ & 1.08( & & & 0.70 & 36) & $1.25(1.07-1.45)^{\mathrm{c})}$ \\
\hline Current pet-keeping & $0.30(0.13-0.71)$ & $1.84(0.93-3.65)$ & $1.51(0.9$ & $1.03(0.47-2.25)$ & $1.02(0.24-4.40)$ & $1.08(0.42-2.83)$ & $0.52(0.29-0.92)$ \\
\hline Mold/dampness & $\left.1.33(1.07-1.66)^{\mathrm{b}}\right)$ & $1.21(0.90-1.62)$ & $\left.1.34(1.09-1.64)^{\mathrm{c}}\right)$ & $1.04(0.78-1.39)$ & $1.22(0.73-2.03)$ & $1.06(0.74-1.51)$ & $\left.1.33(1.09-1.62)^{\mathrm{c}}\right)$ \\
\hline $\begin{array}{l}\text { Windowpane water } \\
\text { condensation }\end{array}$ & $1.33(1.12-1.58)^{\mathrm{c})}$ & $1.36(1.08-1.71)^{\mathrm{c})}$ & $1.12(0.97-1.31)$ & $1.69(1.36-2.11)^{\mathrm{d})}$ & $1.02(0.68-1.54)$ & $0.99(0.75-1.30)$ & $1.13(0.97$ \\
\hline
\end{tabular}

a) Logistic regression was performed by ENTER mode with all the environmental variables added in the model simultaneously, controlling for age, gender, nationality (the Han and minority) and parental asthma/allergic rhinitis (AR)/eczema, put beddings to sunshine and cleaning frequently; aOR, adjusted odds ratio; $12 \mathrm{~m}$, in the last 12 months; AR, allergic rhinitis; DA, doctors' diagnosed asthma; DAR, doctors' diagnosed allergic rhinitis; DP, doctors' diagnosed pneumonia. aORs for environmental variables were calculated based on the reference variables: Live in urban vs. live in suburban/rural; close to traffic/industry/business vs. close to other areas including lake or river; own house vs. renting house; wood/PVC/carpeting floor vs. concrete/stone floor; Wallpaper/painting/wood wall vs. concrete/stone wall; central heating vs. non-central heating system including coal-burning stove, Kang (a heatable brick bed), fireplace, firebasin, floor heating or air conditioning; gas/electricity for cooking vs. coal/wood burning for cooking; home ETS vs. no home ETS; Current pet-keeping: yes vs. no; mold/dampness: yes vs. no; windowpane water condensation: yes vs. no; b) $P<0.05$; c) $P<0.01$; d) $P<0.001$.

winter was consistently associated with wheezing, dry cough and eczema symptoms in the last 12 months. In addition, compared to concrete/tiles or stone material, wood, PVC or carpeting floor material and wallpaper, painting or wood wall material, were positively associated with AR symptoms in the last 12 months. Children with central heating system had a higher prevalence of pneumonia (aOR 1.24,1.05-1.47) but less AR (aOR 0.84, 0.71-0.99) and eczema (aOR 0.64, 0.51-0.81). Home ETS was positively associated with wheezing (aOR 1.23, 1.04-1.46) in the last 12 months and pneumonia (aOR 1.25, 1.07-1.45).

\section{Discussion}

This cross-sectional study of pre-school (2-7 years) children in Urumqi, Xinjiang Uygur Autonomous Region, found that $3.6 \%$ had physician diagnosed asthma, 8.7\% diagnosed AR and $40.9 \%$ had pneumonia. Home signs of mold or dampness and windowpane water condensation were positively associated with asthmatic and rhinitis symptoms. Compared with concrete or stone, wood material/ PVC/ wallpaper or painting in floors and walls were positively associated with rhinitis symptoms in the last 12 months. Use of central heating system, home ETS and home signs of mold or dampness were positively associated with children's pneumonia.

The Chinese national surveys on children's asthma in 1990 and 2000 including Urumqi, reported that the national average of diagnosed asthma in children aged 3-5 years old was $1.25 \%$ in 1990 and $2.32 \%$ in 2000 [2]. There have been few studies of asthma and related diseases in Urumqi preschool children. The study on 6-7 years children in 19951996 reported 7.6\% "asthma ever" using the ISAAC questionnaire, lower than $10.7 \%$ in Beijing using the same questionnaire $(P<0.05)$ [16]. However, how much was physician diagnosed asthma was unknown. A 2011 study in 8 Chinese metropolitan cities found the incidence of asthma (adjusted for age and gender) in children aged 6-13 years in the past 12 months was $1.6 \%$ in Urumqi, higher than for Xi'an $(1.1 \%)$ and Hohhot $(0.9 \%)$ but much lower than for Shanghai $(7.0 \%)$ and Chengdu (4.6\%) [17]. However, it is hard to compare the childhood asthma prevalence between different studies because different definitions of asthma were used and different age children were studied.

We found the prevalence of diagnosed AR of $7.8 \%$, and that of AR reported symptoms in the past 12 months was more than $40 \%$. Zhao et al. [16] reported $7.0 \%$ of AR in Urumqi 6-7 years children's in 1995-1996, compared to $5.3 \%$ in Beijing children, and the prevalence of AR symptoms, such as running or blocking nose without cold to be $31.3 \%$ in Urumqi, compared to the $30.0 \%$ prevalence in Beijing . For Urumqi 13-14 years children, Chen et al. [18] reported the prevalence of AR symptoms of $36.7 \%$, just lower than that in Guangzhou (39.5\%). A 2004 study in 11 Chinese cities conducted by telephone interview found Urumqi had the highest self-reported AR by $21.4 \%$ (age and gender adjusted) in the last 12 months, in which persistent $\mathrm{AR}$, with higher symptom frequency and more severe symptoms, accounted for $36.1 \%$, higher than the average $25.6 \%$ across the 11 cities [19]. It was argued that the 
Urumqi climate, which is arid, cold and windy, with a large temperature difference between day and night, is related with AR symptoms. The annual (1971-2000) average temperature was $7.5-8.2^{\circ} \mathrm{C}$, and relative humidity was $58.2 \%$ and the total water precipitation was $286.3 \mathrm{~mm}$. Finally, Artemisia Vulgaris, a known plant allergen, was found to be the allergen with the highest positive reaction rate in AR children by skin prick test. This study was performed in Shihezi City, close to Urumqi with similar climatic and ecological characteristics [20].

Signs of home dampness and mold growth, as well as windowpane condensation in the winter season were consistently and positively associated with asthma, wheezing, dry cough, AR and eczema symptoms in the last 12 months. The aOR ranged from 1.3-1.7 after controlling for confounding factors. This finding was consistent with the cross-sectional study of 14077 Swedish children aged 1-6 years, which reported four "dampness" indices including visible molds and windowpane condensation were associated with children's asthma, rhinitis and eczema symptoms [21]. In China, Dong et al. [22-24] reported that signs in the home of water damage or visible mold on walls were positively associated with children's asthma symptoms in preschool children and elementary children in northeastern area of China. A recently published 10-year longitudinal study of adults in Uppsala, Sweden, found that signs of dampness in floor construction of any workplace building during follow up (cumulative exposure) were associated with incidence of mucosal symptoms $(\mathrm{OR}=2.43)$ including nasal catarrh, nasal obstruction, dryness in throat, sore throat or irritating cough [25]. Although the exact mechanism is unknown, it has been generally agreed that home mold or dampness is a risk factor for children's allergic diseases including asthma [26-29]. On the other hand, a recently published longitudinal study from Sweden found that self reported dampness or mold could be biased, since the baseline findings of a strong association between dampness and allergies disappeared in the follow-up study 5 years later [30]. This could be due to reporting bias in a country (Sweden) where dampness/ mould is widely educated and known to be risk factors of asthma among population. Such bias is hardly the cause of the associations found in this study, as the general population has little prior knowledge about such an association.

Home decoration and building materials have been reported in relation with children's respiratory symptoms in different areas in the world [24,31,32]. In this study, floors surfaced by wood, PVC or carpeting (totally accounting for $44.7 \%$ ); or walls surfaced by wood, wallpaper or painting (totally accounting for $80.7 \%$ ), were common, and were both positively associated with children's AR symptoms in the last 12 months. Xinjiang Uygur Autonomous Region is undergoing a rapid economic development [3]. Residential buildings in 2010 accounted for $64.2 \%$ of the total yearly new completed construction areas. Organic chemicals including formaldehyde, volatile organic compounds (VOC) or semi-volatile organic compounds (SVOC) have been identified as compounds emitted from floors, walls or furniture made of artificial board or plastics. One study on the indoor formaldehyde level, possibly emitted from wooden floors, has found to be higher in asthmatic children's homes (average $30.2 \mu \mathrm{g} / \mathrm{m}^{3}$ ) than for the control group $\left(27.5 \mu \mathrm{g} / \mathrm{m}^{3}\right)$ in a study in Urumqi [33]. Another case-control study also found that home new decoration was a risk factor for children's asthmatic symptoms with OR of 1.74(1.57-2.64) [34]. How the real mechanisms for these organic compounders affect the AR symptoms needs to be further explored.

Diagnosed pneumonia is reported by around $41 \%$ of children in this study. Globally, pneumonia is the leading single cause of mortality in children aged less than 5 years, and China ranked the second highest in the estimated absolute number of new cases of clinical pneumonia with an incidence rate of 0.22 episode per child-year [35]. Indoor air pollution is a "definite" risk factor for childhood pneumonia [35]. In this study, use of central heating system, home ETS, signs of home mold/dampness and windowpane condensation, were all positively associated with diagnosed pneumonia. A large scale study covering all residents of 33 communities in central Vietnam reported that ETS was independently associated with hospital admissions for pneumonia (adjusted odds ratio 1.55, 95\% CI 1.25 to 1.92) for children under 5 years old [36]. Experimental animal studies showed that tobacco smoke depresses the activities of alveolar macrophages, impairs mucociliary clearance, enhances bacterial adherence, disrupts the respiratory epithelium and decreases the serum Ig levels [37]. Thus, a significant relationship between ETS and childhood pneumonia is likely. In China, passive smoking has been considered as a risk factor associated with children's respiratory diseases, including pneumonia [38]. Home mold or dampness is potentially an indicator of microbiological pollution including bacteria, fungi or virus, as well as poor indoor ventilation. Respiratory infections are more common in this indoor environment [39], which increases the risk of pneumonia [40]. The association between central heating system and pneumonia is difficult to explain. The lower indoor air ventilation by using the central heating system in winter season due to more window closing could be partly the explanation.

Additionally, central heating system was negatively associated with AR symptoms and eczema symptoms in the last 12 months as well as DAR. It is understandable due that this association was based on the comparison with other more polluting heating systems (coal-burning stove, Kang (a heatable brick bed), fireplace, firebasin, floor heating or air conditioning) which may produce complex chemicals or compounds during burning. Current pet-keeping was found to be negatively associated with children's pneumonia as well as for wheezing in the last 12 months. By further analyses, it showed that there was a higher proportions of pet avoidance behavior (get rid of pets due to allergic diseases) 
in homes with current pets keeping $(9.0 \%, 11 / 122)$ than in homes without $(3.45,66 / 1941)$, which indicated the potential presence of "Healthy pet-keeping" effect [41]. Thus it is prudent to conclude pet-keeping was protective for these two health effects. Further deep research is needed to explore the possible mechanisms in the future.

\section{Conclusions}

In conclusion, high prevalence of asthmatic, AR symptoms and pneumonia in preschool children were found in Urumqi. Home signs of mold growth or dampness, windowpane condensation, as well as interior surface materials emitting chemicals and ETS were likely the risk factors. This is one of the few large-scale studies on childhood respiratory diseases in relation to home environment in Urumqi City. Further research including longitudinal follow-up study design is needed to verify and confirm the current findings.

This work was supported by the National Natural Science Foundation of China (30800894, 71173045). Grateful appreciation to Louise B. Weschler for her hard work on language proof. Many thanks for the participating children and teachers in the day care centers in Taiyuan City.

1 Asher M I, Montefort S, Bjorksten B, et al. Worldwide time trends in the prevalence of symptoms of asthma, allergic rhinoconjunctivitis, and eczema in childhood: ISAAC Phases One and Three repeat multicountry cross-sectional surveys. Lancet, 2006, 368: 733-743

2 Chen Y Z. Comparative analysis of the state of asthma prevalence in children from two nation-wide surveys in 1990 and 2000 year (in Chinese). Zhonghua Jie He He Hu Xi Za Zhi, 2004, 27: 112-116

3 Statistics Bureau of Xinjiang Uygur Automomous Region, Xinjiang Statistical Yearbook 2011. Urumqi: China Statistic Press, 2012

4 Mamtimin B, Meixner F X. The characteristics of airpollution in the semi-arid city of Urumqi (NW China) and its relation to climatological process. Geophysi Res Abstr, 2007, 9: 06537

5 Mamtimin B, Meixner F X. Air pollution and meteorological processes in the growing dryland city of Urumqi (Xinjiang, China). Sci Total Environ, 2011, 409: 1277-1290

6 Qiao L P, Wu S Q, Wang P D, et al. Survey and analyses on asthmm, allergici rhinitis and eczema in children (in Chinese). Xinjiang Yixue, 2003, 33: 34-35

7 Bornehag C G, Sundell J, Sigsgaard T. Dampness in buildings and health $(\mathrm{DBH})$ : Report from an ongoing epidemiological investigation on the association between indoor environmental factors and health effects among children in Sweden. Indoor Air, 2004, 14(Suppl 7): 59-66

8 Naydenov K, Popov T, Mustakov T, et al. The association of pet keeping at home with symptoms in airways, nose and skin among Bulgarian children. Pediatr Allergy Immunol, 2008, 19: 702-708

9 Tham K W, Zuraimi S, Koh D, et al. Associations between home dampness and presence of molds with asthma and allergic symptoms among young children in the tropics. Pediatr Allergy Immunol, 2007, 18: 418-424

10 Sun Y, Sundell J. Life style and home environment are associated with racial disparities of asthma and allergy in Northeast Texas children. Sci Total Environ, 2011, 409: 4229-4234

11 Hsu N Y, Wu P C, Bornehag C G, et al. Feeding bottles usage and the prevalence of childhood allergy and asthma. Clin Dev Immunol, 2012, doi:10.1155/2012/158248

12 Mi Y H, Norback D, Tao J, et al. Current asthma and respiratory symptoms among pupils in Shanghai, China: Influence of building ventilation, nitrogen dioxide, ozone, and formaldehyde in classrooms. Indoor Air, 2006, 16: 454-464

13 Norback D, Zhao Z H, Wang Z H, et al. Asthma, eczema, and reports on pollen and cat allergy among pupils in Shanxi province, China. Int Arch Occup Environ Health, 2007, 80: 207-216

14 Zhao Z Z, Zhang Z, Wang Z H, et al. Asthmatic symptoms among pupils in relation to winter indoor and outdoor air pollution in schools in Taiyuan, China. Environ Health Perspect, 2008, 116: 90-97

15 Chan H H, Pei A, Van Krevel C, et al. Validation of the Chinese translated version of ISAAC core questions for atopic eczema. Clin Exp Allergy, 2001, 31: 903-907

16 Zhao T, Wang H J, Chen Y, et al. Prevalence of childhood asthma, allergic rhinitis and eczema in Urumqi and Beijing. J Paediatr Child Health, 2000, 36: 128-133

17 Li F, Zhou Y, Li S, et al. Prevalence and risk factors of childhood allergic diseases in eight metropolitan cities in China: A multicenter study. BMC Public Health, 2011, doi: 1186/1471-2458-11-4377

18 Chen Y Z, Zhao T B, Yan D, et al. A questionnaire-based survey on prevalence of asthma, allergic rhinitis and eczema in five Chinese cities (ISAAC study). Chin J Pediatr, 1998, 36: 353-355

19 Zhang L, Han D, Huang D, et al. Prevalence of self-reported allergic rhinitis in eleven major cities in china. Int Arch Allergy Immunol, 2009, 149: 47-57

20 Han Y, Zhang H. Epidemiological investigation of allergic rhinitis in the primary school students in grade three of Shihezi city (in Chinese). J Clin Otorhinolaryngol Head Neck Surg, 2009, 23: 10741078

21 Bornehag C G, Sundell J, Hagerhed-Engman L, et al. 'Dampness' at home and its association with airway, nose, and skin symptoms among 10851 preschool children in Sweden: A cross-sectional study. Indoor Air, 2005, 15(Suppl 10): 48-55

22 Dong G H, Ding H L, Ma Y N, et al. Housing characteristics, home environmental factors and respiratory health in 14729 Chinese children. Rev Epidemiol Sante Publique, 2008, 56: 97-107

23 Dong G H, Ma Y N, Ding H L, et al. Housing characteristics, home environmental factors and respiratory health in 3945 pre-school children in China. Int J Environ Health Res, 2008, 18: 267-282

24 Dong G H, Ma Y N, Ding H L, et al. Effects of housing characteristics and home environmental factors on respiratory symptoms of 10784 elementary school children from northeast china. Respiration, 2008, 76: 82-91

25 Zhang X, Sahlberg B, Wieslander G, et al. Dampness and moulds in workplace buildings: Associations with incidence and remission of sick building syndrome (SBS) and biomarkers of inflammation in a 10 year follow-up study. Sci Total Environ, 2012, 430C: 75-81

26 Spengler J D, Jaakkola J J, Parise H, et al. Housing characteristics and children's respiratory health in the Russian Federation. Am J Public Health, 2004, 94: 657-662

27 Tischer C, Chen C M, Heinrich J. Association between domestic mould and mould components, and asthma and allergy in children: A systematic review. Eur Respir J, 2011, 38: 812-824

28 Bornehag C G, Blomquist G, Gyntelberg F, et al. Dampness in buildings and health. Nordic interdisciplinary review of the scientific evidence on associations between exposure to "dampness" in buildings and health effects (NORDDAMP). Indoor Air, 2001, 11: 72-86

29 Bornehag C G, Sundell J, Bonini S, et al. Dampness in buildings as a risk factor for health effects, EUROEXPO: A multidisciplinary review of the literature (1998-2000) on dampness and mite exposure in buildings and health effects. Indoor Air, 2004, 14: 243-257

30 Larsson M, Hagerhed-Engman L, Moniruzzaman S, et al. Can we trust cross-sectional studies when studying the risk of moisture-related problems indoor for asthma in children? Int J Environ Health Res, 2011, 21: 237-247

31 Jaakkola J J, Parise H, Kislitsin V, et al. Asthma, wheezing, and allergies in Russian schoolchildren in relation to new surface materials in the home. Am J Public Health, 2004, 94: 560-502

32 Larsson M, Hagerhed-Engman L, Kolarik B, et al. PVC-as flooring material—and its association with incdent asthma in a Swedish child 
cohort study. Indoor Air, 2010, 20: 494-501

33 Muzhapaer D, Xu P, TAji G. The correlation between childhood asthma and air pollution after household renovation (in Chinese). $\mathrm{J}$ Clin Ped, 2007, 25: 20-22

34 Ybulayin X, Yan H. Investigation on relationship between indoor air pollution and asthma in children (in Chinese). End Dis Bull, 2008, 23: 3-5

35 Rudan I, Boschi-Pinto C, Biloglav Z, et al. Epidemiology and etiology of childhood pneumonia. Bull World Health Organ, 2008, 86: 408-416

36 Suzuki M, Thiem V D, Yanai H, et al. Association of environmental tobacco smoking exposure with an increased risk of hospital admissions for pneumonia in children under 5 years of age in Vietnam. Thorax, 2009, 64: 484-489
37 Kum-Nji P, Meloy L, Herrod H G. Environmental tobacco smoke exposure: Prevalence and mechanisms of causation of infections in children. Pediatrics, 2006, 117: 1745-1754

38 Niu J P, Li R. Health effects of passive smoking on children (in Chinese). J Environ Health, 2003, 20: 287-288

39 Stark P C, Burge H A, Ryan L M, et al. Fungal levels in the home and lower respiratory tract illnesses in the first year of life. Am J Respir Crit Care Med, 2003, 168: 232-237

40 Chen S C, Blyth C C, Sorrell T C, et al. Pneumonia and lung infections due to emerging and unusual fungal pathogens. Semin Respir Crit Care Med, 2011, 32: 703-716

41 Bornehag C G, Sundell J, Hagerhed L. Pet-keeping in early childhood and airway, nose and skin symptoms later in life. Allergy, 2003, 58: 939-944

Open Access This article is distributed under the terms of the Creative Commons Attribution License which permits any use, distribution, and reproduction in any medium, provided the original author(s) and source are credited. 